\title{
Perceived Depression among Cancer Patients and Non - Cancer Normal People: A Comparative Study with Reference to Bihar, India
}

\begin{tabular}{c} 
Dr. Aparna Rani \\
\hline Clinical Psychologist, C/O. Dr. Ambrish T \\
Article History \\
Received: 29.09 .2020 \\
Accepted: 18.10 .2020 \\
Published: 23.10 .2020 \\
Journal homepage: \\
https://www.easpublisher.com/easjpbs
\end{tabular}

Abstract:Depression, as a disease, is common in cancer patients. It is generally observed that various cancer patients report most of the time unfolds that they are suffering from depression, although depression is a difficult task to study in cancer patients. Hence, the present study was aimed at studying the perceived depression among cancer patients with special reference to Bihar state, India. The present study is important as it has been shown that patients with depression which tend to have drastic symptoms. To achieve the objective of the present study total sample consisted of eighty $(\mathrm{N}=80)$ cancer patients covering cervical and breast cancer patients comprising male $(n=45)$ and female $(n=35)$ were selected through incidental-cum-purposive sampling technique from the Swami Vivekanand Cancer Sansthan, Darbhanga, and Mahavir Cancer Sansthan, Patna and moreover equal number of non - cancer normal people were also selected for making comparative study. Beck Depression Inventory along with biographical information blank (BIB) were administered to collect the data. Having collected the data on the items of the inventory, the individual scores were summed up for giving statistical treatment. Finally, results revealed the fact that there is higher degree of significant difference between the group of cancer patients and normal people as " $t$ " has been found highly significant at .01 level of confidence, although significant difference has also been found among the group of male and female cancer patients. It is very interesting to point out here that Male group of Cancer patients had shown higher level of depression in comparison to female group of cancer patients. Obtained results have been discussed in detail by giving probable reasons.

Keywords:Depression, Cancer Patients, Bihar, India.

Copyright ( 12020 The Author(s): This is an open-access article distributed under the terms of the Creative Commons Attribution 4.0 International License (CC BY-NC 4.0) which permits unrestricted use, distribution, and reproduction in any medium for non-commercial use provided the original author and source are credited.

\section{INTRODUCTION}

Several Studies reveal the fact that the number of women diagnosed with breast cancer and on the other hand men diagnosed with throat cancer which are increasing day by day not only in India but throughout the nations of the world. It is seen as a terrifying disease due to its high mortality rate and its impacts on the selfimage and the sexual relationship. Many patients experience psychological reactions and may have psychiatric illness or diseae. Thus, the present investigation was aimed at studying the perceived depression among cancer patients in comparison to normal people with particular reference to Bihar State.

Cancer or Carcinoma is a malignant and the terms neoplasm and tumor are approximate synonyms. A cancer is morbid swelling or enlargement, a mass of new tissue biologically detrimental to the organism that persists and grows in dependently of surrounding structures the term includes a wide variety of pathological types. With increasing mean ages in the general population, cancer has become increasingly important as a major decease producing incapability and health [1].

To grow old and to die is universally accepted as part of the natural order of things. But to die of cancer at old age, or at any other time, is not considered natural but a tragedy [2].

When we think of cancer in general terms we are apt to conjure up a process characterized by a steady, remorseless and inexorable progress in which the disease is all conquering, and none of the immunological and other defensive forces which help us to survive the onslaught of bacterial and viral infections can serve to halt the faltering footsteps to the grave [3].

The word cancer strikes fear into the hearts and minds of many people, laypersons and health 
providers alike. There are several prevalent but inaccurate generalization about cancer that cause fear: (1) cancer can occur without, warning so that it is too late for medical intervention; (2) medical intervention is not very effective in stopping cancer; (3) because cancer uses most of the body's nutrients, the body wastes away while the cancer thrives; (4) advanced cancer causes unmanageable pain that is not responsive to pain killing medication; (5) persons with cancer are often abandoned because family, friends, and health providers feel there is little hope (6) the diagnosis of cancer is difficult and effective treatment cannot be implemented until the cancer is far along; (7) treatment of cancer is painful and mutilating; (8) the cause of cancer is unknown and persons have little control over whether they will get cancer; and (9) persons have little control over cancer once they get it; even if they cooperate fully with health providers, treatment is unsuccessful $[4,2]$.

The role of environmental, behavioral, and psychosocial factors in the etiology and course of cancer will be examined. The impact of cancer and its diagnosis and treatment will also be described. Let us begin by defining cancer and its manifestations.

Cancer does not have uniform symptoms. It is not one disease. Over one hundred different types of cancer have been identified. However, all cancers have some common characteristics. Cancer involves an alteration in a normal cell or group of cells such that they proliferate rapidly because normal mechanisms that inhibit cellular growth are impaired. With timer, cancer cells may spread from their original site to adjacent tissue by infiltration, often via the lymphatic and circulatory systems. Some cancer cells may break off their original site and circulate until they lodge in other tissues in the body. If these tissues provide a suitable environment, the cancer cells may invade them and proliferate, a process called metastasis $[5,6]$. Various studies on different kinds of cancer has been studied but none of the studies have been found with particular reference to Bihar State.

Breast cancer is the most frequently diagnosed cancer and the leading cause of cancer deaths among females worldwide and the second most common cancer overall Ferlay J, Soerjomataram I, Ervik M et al. [7].

Studies have shown that prevalence of psychological distress among breast cancer patients is high, and they are at higher risk of developing severe anxiety and depression Mehnert A, Koch U [8]; Burgess C, Cornelius V, Love S, Graham J, Richards M et al. [9]. Cancer may induce the development of psychiatric disorders especially among women whom having breast cancer and these effects can be on both the patients and their family members [10]. Depression and anxiety are the two most common psychiatric comorbidities present among breast cancer patients (Baumeister H, Kriston L, Bengel J, Härter M [11]; Härter M, Reuter K, Aschenbrenner A, Schretzmann B, Marschner N et al. [12].

Recently, one of the important studies on anxiety, depression and perceived stress among breast cancer patients has been conducted by Alagizy, Soltan and Gohar [13] and they viewed that the prevalence of depressive symptoms, anxiety symptoms, and perceived stress were found $68.6 \%, 73.3 \%$, and $78.1 \%$ respectively. Moderate to severe anxiety, depression, and stress were found more prevalent among advanced disease patients, patients who underwent surgery, married patients who were living in rural areas, illiterate, and those without satisfactory income but without statistically significant difference except for the effect of occupation on the anxiety state as unemployed patients had significantly higher prevalence of moderate to severe anxiety $(100 \%)$ than employed patients. They also concluded that depressive disorders, anxiety, and perceived stress are common psychiatric disorders among the breast cancer patients.

\section{AIMS AND OBJECTIVE OF THE PRESENT STUDY}

Having surveyed the review of literature on the problem cited above, it has been found that various researches have been found on different aspects of psychological depression among people in general and cancer patients in particular but very meager number of studies especially in Indian context has been found on cancer patients in term of depression. These days, every one experience stress and it causes little amount of depression. Therefore, the present study was aimed at studying depression among cancer patients and non cancer patients. The present investigation was planned to study on the sample area of Bihar state, India. It is very important to mention here that the area taken for the present piece of research work is still unexplored and need special attention. Thus, the problem chosen by the present investigator is of utmost value and will fill the void of knowledge in the area concerned.

\section{HYPOTHESES}

On the basis of the broad aims and objectives of the present study, the following hypotheses were formulated:

1. There will be no significant difference between the group of cancer patients (Experimental group) and Non - cancer people living in Bihar State (control group) in terms of their degree of Depression.

2. Non - Cancer normal people will have higher degree of perceived reactions on depression than Cancer patient group.

3. There will be no significant difference between the group of male and female cancer patients on the degree of Beck Depression Inventory. 
4. Female cancer patients will have higher degree of depression than male cancer patient especially in Bihar, India from where the present pieces of research work have been carried out.

\section{Research methodology}

To carry out the present piece of research work the following sound methodology was used:

\section{Sample}

Total sample consisted of eighty $(\mathrm{N}=80)$ cancer patients covering cervical and breast cancer patients comprising male $(n=45)$ and female $(n=35)$ were selected through incidental-cum-purposive sampling technique from the Swami Vivekanand Cancer Sansthan, Darbhanga, and Mahavir Cancer Sansthan, Patna. The mean age of patients was 50.350 and S.D. was 10.21 and equal numbers of normal people were also taken. The mean age of normal people was 38.72 with an SD was 9.43.

\section{Tools Used}

For measuring the levels of depression among visually impaired and non - visually impaired students the following tools were used for the present piece of research work.

1. Beck Depression Inventory: For measuring depression among students - a Hindi Version of Beck Depression Inventory developed by Arora et al.[14] was used. This is an objective questionnaire containing 20 items with 4 alternatives $(0-3)$ measures severity of depression that follows:

\section{Total ScoreLevels of Depression}

\begin{tabular}{ll}
\hline $0-0$ & No depression \\
$1-10$ & these ups and downs are considered \\
& normal
\end{tabular}

\section{Considered Normal}

$\begin{array}{ll}11-16 & \text { mild mood disturbance } \\ 17-20 & \text { border line clinical depression } \\ 21-30 & \text { moderate depression } \\ 31-40 & \text { severe depression } \\ \text { Over } 40 & \text { extreme depression }\end{array}$

\section{Biographical Information Blank (BIB):} Biographical blank was also prepared for interpreting the results. It includes: sex, qualification, religion, area of locality, family income, father's qualification, mother's qualification, family structure, etc.

\section{Procedure}

Before giving the above schedules, respondents were deliberated about the instructions of questionnaire schedule then thereafter measures were given to each cancer patients (Experimental group) individually to complete in all respect. They were also assured that the information provided by them would be kept strictly confidential and will be used research purposes only. Likewise, questionnaire schedule were also give to non - cancer normal people (Control group). Having collected the data using Hindi version of Beck Depression Inventory, the individual scores were summed up for giving statistical treatment. Finally, the obtained results of both the group presented in tables and discussed in detail.

\section{RESULTS AND DISCUSSION}

In quest of obtaining the results, descriptive analysis was done by computing mean, $\mathrm{SD}$, and t-test to see the significant difference between the groups of cancer patients and non - cancer normal people. From the table-1, it can be observed that in the present sample there is a highly significant difference in the mean values of total depression inventory as cancer patients (experimental group) had shown moderate degree of depression as the mean score with an SD (30.37 and 7.58) than non - cancer normal people (control group) (Mean - 14.21 and SD - 3.31). Hence, the significant difference between cancer patients and non - cancer normal people has been found highly significant as $t$ value i.e. 17.38 is found to be significant statistically at .01 level of confidence. Thus, the null hypothesis that there will be no significant difference between the group of visually impaired school going children (Experimental group) and Non - visually impaired students (control group) in terms of their degree of Depression, stands rejected. The results seem to be logical that cancer patients and Non- cancer normal people do differ in their degree of depression. It is due to the psycho - social make up of their personality. It is important to mention here that one of the possible reasons for the present study is likely to be lack of awareness about the importance of education pertaining to the causes and symptoms of cancer especially from where the sample has been drawn.. Thus, the cancer patient group is found to have more depression than non - cancer common people (control group), although, government, NGOs and other agencies always highlighted the outcomes of different types of cancer disease among the people.

Table-1: Showing Mean, SD and t-value between the groups of Cancer Patients and Non - Cancer Normal People of Bihar State In terms of Their Degree of Depression

\begin{tabular}{|c|c|c|c|c|c|}
\hline \\
\hline Variable & Groups & $\mathbf{N}$ & Mean & SD & t-value \\
\hline \multirow[b]{2}{*}{$\begin{array}{l}\text { Beck Depression } \\
\text { Inventory }\end{array}$} & $\begin{array}{c}\text { Cancer Patients (Cervical \& } \\
\text { Brest Cancer) }\end{array}$ & 80 & 30.37 & 7.58 & \multirow[b]{2}{*}{$17.38 *$} \\
\hline & Non - Cancer Normal People & 80 & 14.21 & 3.31 & \\
\hline
\end{tabular}

* Significant at 0.01 Levels 
Table -2 is the extension of table -1 regarding the comparative levels of degree of depression between the group of cancer patients and non - cancer common people of Bihar, India.

Table-2: Showing Comparative Levels of Depression between Cancer Patients and Non - Cancer Normal People of Bihar State, India

\begin{tabular}{|c|c|c|c|c|}
\hline \multirow[t]{2}{*}{ Levels } & \multicolumn{2}{|c|}{$\begin{array}{c}\text { Cancer Patients } \\
\text { (Experimental Group) }\end{array}$} & \multicolumn{2}{|c|}{$\begin{array}{c}\text { Non - Cancer Normal People } \\
\text { (Control Group) }\end{array}$} \\
\hline & $\mathrm{n}=80$ & Percentage & $\mathrm{n}=80$ & Percentage \\
\hline High & 56 & $70.00 \%$ & 35 & $43.75 \%$ \\
\hline Moderate & 18 & $22.5 \%$ & 29 & $36.25 \%$ \\
\hline \multirow[t]{2}{*}{ Low } & 06 & $7.5 \%$ & 16 & $20 \%$ \\
\hline & (Moderate & $\begin{array}{l}.37 \\
\text { as per norms) }\end{array}$ & (Mild mood & 21 \\
\hline
\end{tabular}

Table - 2 highlights the percentages of perceived reaction of the degree of depression between the group cancer patients and Non - cancer common people from where the present piece of research work has been carried out. It is evident from the table - 2 that 70 percent of cancer patients have shown higher degree of depression (moderate level of depression as per norm) as compared to non - cancer common people who reported 43.75 percent to have mild mood disturbance only as per the norms of the inventory While 22.5 percent of cancer patients have shown moderate level of perceived reactions on depression, 36.25 percent of non - cancer normal people group have shown moderate level of mild moderate level of depression which is comparatively high when compared to cancer patients. Moreover, 20 percent of common normal people reported to have low level of moderate depression in comparison to cancer patients group i.e. 7.5 percent which is low degree of mild mood disturbance comparatively as compared. Therefore, the proposed hypothesis i.e. cancer patients will not be differing with non - cancer common people on the levels of the degree of depression, stands also rejected. The obtained results seem to be logical in the sense that cancer patients have been found to have moderate depression as per norms of the inventory, it is due to the feeling of sadness, tearfulness, emptiness or hopelessness as compared to non- cancer common people (control group). The above mentioned results regarding the levels of the degree of depression between cancer patients and non - cancer common people can also be observed by the following figure:

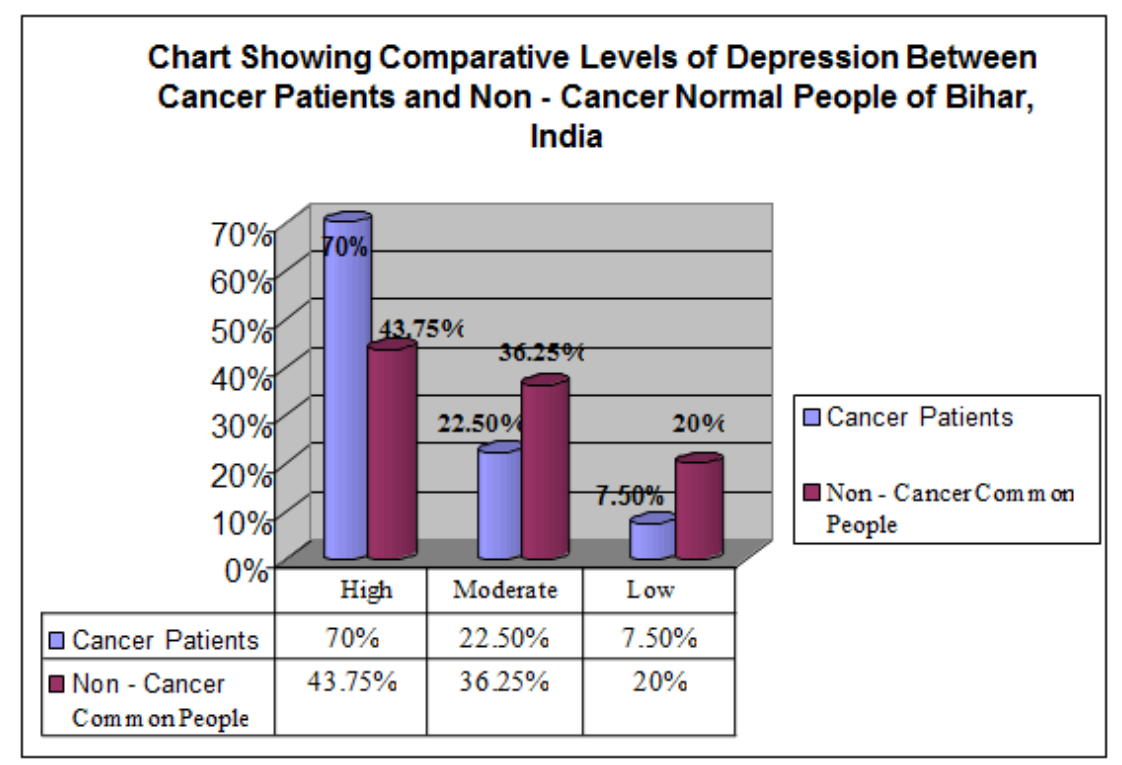

Table-3 Showing Mean, SD and t-value between the groups of Female Cancer Patients and Male Cancer Patients

\begin{tabular}{|c|c|c|c|c|c|}
\hline \multirow{2}{*}{ Variable } & \multicolumn{2}{|c|}{ of Bihar In terms of Their Degree of Depression } & \multicolumn{2}{|c|}{ t-value } \\
\hline \multirow{3}{*}{$\begin{array}{c}\text { Beck Depression } \\
\text { Inventory }\end{array}$} & Male Cancer Patients & $\mathbf{4 5}$ & $\mathbf{2 9 . 3 6}$ & $\mathbf{7 . 3 4}$ & \multirow{2}{*}{$\mathbf{3 . 2 3}$} \\
\cline { 2 - 6 } & Female Cancer Patients & 35 & $\mathbf{2 4 . 4 5}$ & $\mathbf{6 . 1 1}$ & \\
\hline
\end{tabular}

* Significant at 0.01 Levels 
In addition to the above aforementioned results of table $-1 \& 2$, table -3 of the results clearly depicts the picture pertaining to the significance of difference between the groups of female and male cancer patients in terms of their degree of perceived depression. It could be observed from the table -3 that both the group (male and female) of cancer patients have reported to have moderate level of depression as per the norms of Beck Depression Inventory as the mean values with an SDs are 29.36, 7.34 and 24.45, 6.41 respectively. Therefore, significant difference have been found $(\mathrm{t}=$ 3.23 ) statistically at 0.01 level of confidence. Hence, the proposed hypothesis i.e. there will be no significant difference between the group of male and cancer patients in their degree of perceived depression, stands rejected. Extending the table -3 of the results presented, table -3 of the results have clearly indicated that male group of cancer patients suffer more from the evils of depression, as the obtained mean score have been found as high in comparison to female cancer patients which can be observed from the table -3 . That's why the proposed hypothesis i.e. female cancer patients will not have higher degree of depression than male cancer patients also stands rejected.

Table-4: Showing Comparative Levels of Depression among Male Cancer Patients and Female Cancer Patients of Bihar, India

\begin{tabular}{|c|c|c|c|c|}
\hline \multirow{2}{*}{ Levels } & \multicolumn{2}{|c|}{ Male Cancer Patients } & \multicolumn{2}{c|}{ Female Cancer Patients } \\
\cline { 2 - 5 } & $\mathbf{n = 4 5}$ & Percentage & $\mathbf{n = 3 5}$ & Percentage \\
\hline High & $\mathbf{2 4}$ & $\mathbf{5 3 . 3 3 \%}$ & $\mathbf{1 9}$ & $\mathbf{5 4 . 2 9 \%}$ \\
\hline Moderate & $\mathbf{1 5}$ & $\mathbf{3 3 . 3 3 \%}$ & $\mathbf{1 1}$ & $\mathbf{3 1 . 4 3 \%}$ \\
\hline Low & $\mathbf{6}$ & $\mathbf{1 3 . 3 3 \%}$ & $\mathbf{5}$ & $\mathbf{1 4 . 2 8 \%}$ \\
\hline & \multicolumn{3}{|c|}{ Mean $=\mathbf{2 9 . 3 6}$} & \multicolumn{2}{c|}{ Mean $=\mathbf{2 4 . 4 5}$} \\
& \multicolumn{2}{c}{ Moderate Depression as per norms } & \multicolumn{2}{c}{ Moderate Depression as per norms } \\
\hline
\end{tabular}

Extending the table -3 of the results, table -4 is also showing comparative levels of depression among male and female cancer patients from where the present piece of research work has been carried out. From the table -4 , it could be understood that 54.29 percent of female cancer patients have shown higher level of the degree of depression as compared to male cancer patients i.e. 53.33 percent. 31.43 percent of female cancer patients have shown moderate level of depression in comparison to their male counterparts i.e.
33.33. Similarly, 13.33 percent of male cancer patients have shown low levels of the degree of depression as compared to their female counterparts' i. e. 13.33 percent. It is important to mention here that both the group of male and female cancer patients have reported moderate levels of depression as per the norms prepared by Beck on Beck's Depression Inventory. Obtained results as mentioned above can also be observed by the following figures:

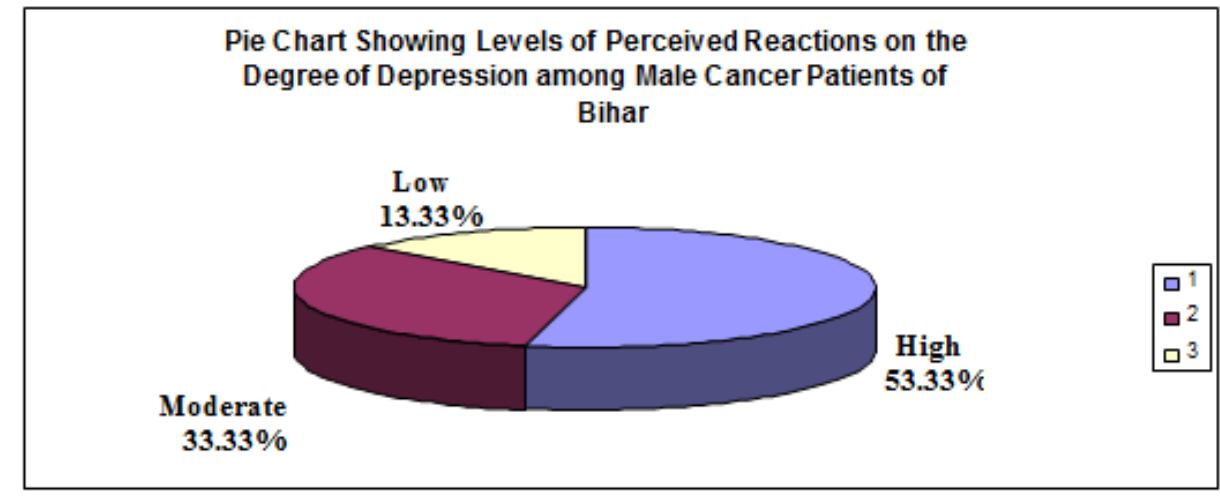




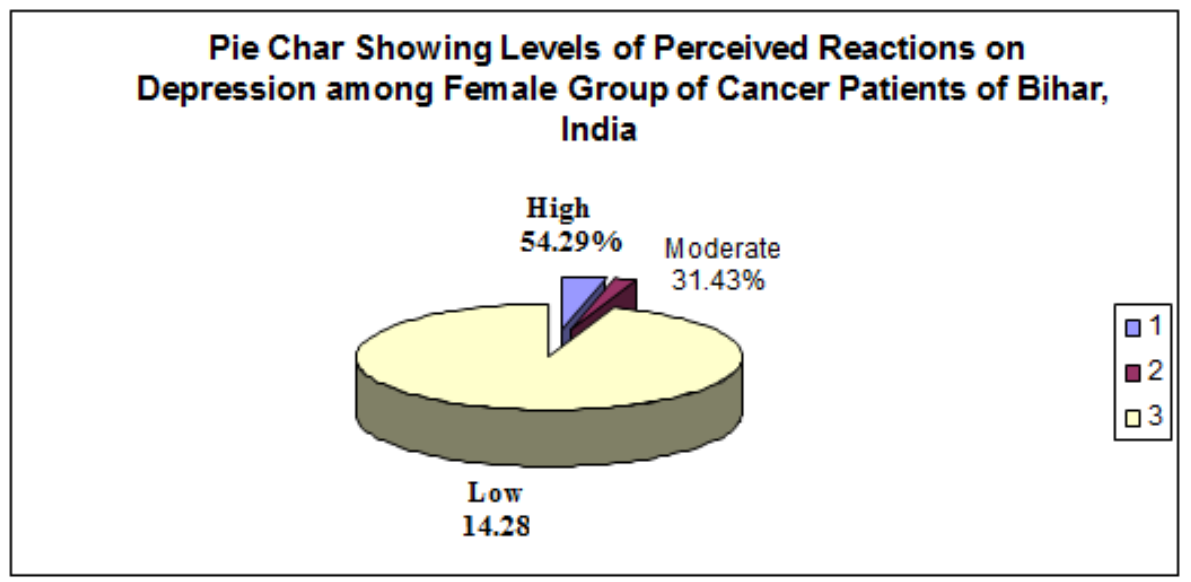

Discussing the obtained results presented in tables -1 to 4 it is important to point out some of the observations pertaining to male and female cancer patients of Bihar from where the present sample has been undertaken for the present piece research work i.e. there is a need to pay much more attention towards the evils of cancer especially in terms of depression. Basically depression is more dangerous than any disease even cancer. Hence, Union and State Government must take care of. It is a challenge not only to encourage the cancer patients but also to improve the personality development of the normal people.

A large number of studies on depression, anxiety and stress have been studied in the psychiatric literature but do not study specific sample especially cancer patients. An advantage of the present study is the specific sample composed of cancer patients. It is because of the fact that if necessary precautions provided to the any type of patients especially to cancer patients then thereafter every patients even cancer patients could be cured from the psychological disorder viz., depression, anxiety, and stress. This is the era of stress, anxiety and depression which is now leading to death. For this reason, the sample size is relatively low. The cross-sectional quality of the present study is a limitation. It might be useful to study longitudinally with different type of patients, viz. neurotic and psychoneurotic as well.

Therefore, it is important to mention that every patients must be taken care by the teachers, doctors, parents, society, NGOs, Government Officials, etc especially in Bihar State in particular and Nation at large.

\section{LIMITATION OF THE STUDY}

The present study lack generality because the present study was conducted in a single facility with outpatients, was one of the limiting factors for generalization of the results. Further, longitudinal studies on larger population are needed to ascertain our findings. Hence, the larger of varied sample is needed to understand the behaviour of the cancer patients. There may some other limitations of the study as the other associated factors for distress were not included in the current study such as pain, financial support, family background, physical suffering, and social support. We only studied the levels of perceived reactions between the group of cancer patients and normal people. For future analysis, the association between distress with anxiety and depression could be studied for later period to measure the effect of psychological and lifestyle factors on prognosis of patients.

\section{CONCLUSIONS}

The conclusions have been drawn on the basis of obtained results and its interpretations that follow:

1. Significant difference have been found between the group of Cancer Patients (Experimental group) and Non - Cancer normal people (control group) in terms of their degree of Depression in Bihar, India.

2. Cancer patients have been found more prone to higher degree of perceived reactions on depressions than non - cancer normal group.

3. Significant difference has also been found between male and female cancer patients on their degree of perceived reactions on depression in Bihar State

4. Male cancer patients have been found to have higher degree of perceived reactions on depression than female group of cancer patients.

5. Observations have revealed the fact that there is a need to pay much more attention for providing best treatment psychologically then it would be possible to protect the patients either they are suffering from any type of cancer disease or other psychological disorders. It is because of the fact that they are the part of our family and society and they have the right to participate in each event of our nation, that's why it is strongly suggested that our union / state government, researchers, family, society and NGOs must take action to create confidence among the patients in general and cancer patients in particular by providing special needs especially in region 
from where the present piece of research work has been completed.

6. Finally, it is to mention here that the findings of the present study may provide some light for further investigations into a topic that, to our knowledge, had never been previously studied in Bihar, India.

\section{ACKNOWLEDGEMENT}

Author expresses her gratitude to Dr. Ambrish Thakur, Baba Jhum Raj Medical, Deoghar (Jharkhand) who gave their support more than one way to complete this research work and to all the respondents for giving their cooperation in responding to the items of the questionnaires during the study.

\section{REFERENCES}

1. Pestonjee, D. M. (2006), stress and coping. The Indian experience. New Delhi: Sage Publications.

2. Miller, D.G. (1980). On the nature of susceptibility to cancer. Cancer, 46, 1307-1318.

3. Boyd. W. (1966). The spontaneous regression of cancer. Springfield. IL: Charles C. Thomas.

4. Clark. R.L. (1976). Psychologic reactions of patients and health professionals to cancer. In J.W. Cullen, B.H. Fox, \& R.N. Isom (eds) Cancer: The behavioral dimensions 207-231. New York: Raven Press.

5. Baldanado. A., Stahl. D. (1978). Cancer nursing: A holistic, multidisciplinary approach. Garden City. NY: Medical Examination.

6. Poste, G. (1977). The cell surface and metastasis. In S. Day, W. Myers, P. Stansley, S. Garattini, \& M. Lewis (Eds.), Cancer "wasion and metastasis: Biological mechanism, and therapy, 1948. New York: Raven Press.

7. Ferlay, J., Soerjomataram, I., Ervik, M., Dikshit, R., Eser, S., Mathers, C., ...\& Bray, F. (2014). GLOBOCAN 2012 v1. 0, Cancer Incidence and
Mortality Worldwide: IARC CancerBase No. 11 [Internet]. 2013, International Agency for Research on Cancer. Avaliable at: http://globocan. iarc. fr.

8. Mehnert, A., Koch, U. (2008). Psychological comorbidity and health-related quality of life and its association with awareness, utilization and need for psychosocial support in a cancer register based sample of long-term breast cancer survivors. $J$ Psychosom Res, 64:383-391

9. Burgess, C., Cornelius, V., Love, S., Graham, J., Richards, M. (2005). Depression and anxiety in women with early breast cancer: five year observational cohort study. BMJ 330:402-705

10. Ahmet, A., Eda, U., Umut V. (2014). Depression, anxiety and sexual satisfaction in breast cancer patients and their partners-izmir oncology group study. Asian Pac J Cancer Pre, 15:10631-10636

11. Baumeister, H., Kriston, L., Bengel, J., \&Härter, M. (2010). High agreement of self-report and physician-diagnosed somatic conditions yields limited bias in examining mental-physical comorbidity. Journal of clinical epidemiology, 63(5), 558-565.

12. Härter, M., Reuter, K., Aschenbrenner, A., Schretzmann, B., Marschner, N., Hasenburg, A., \& Weis, J. (2001). Psychiatric disorders and associated factors in cancer: results of an interview study with patients in inpatient, rehabilitation and outpatient treatment. European Journal of Cancer, 37(11), 1385-1393.

13. Alagizy, H. A., Soltan, M. R., Soliman, S. S., Hegazy, N. N., \&Gohar, S. F. (2020). Anxiety, depression and perceived stress among breast cancer patients: single institute experience. Middle East Current Psychiatry, 27(1), 1-10.

14. Arora, R., \&Palta, J. P. (1989). Perturbation of membrane calcium as a molecular mechanism of freezing injury. In Environmental stress in plants (pp. 281-290). Springer, Berlin, Heidelberg. 